\title{
Learning by Employing Educational Multimedia in Field-dependent and Field-independent Cognitive Styles
}

\author{
Mohamad Javad Karamaerouz ${ }^{1, *}$, Ali Abdi ${ }^{2}$, Soosan Laei ${ }^{1}$ \\ ${ }^{1}$ Department of Educational Sciences, faculty, Kermanshah Branch, Islamic Azad University, 6718997551, Kermanshah, Iran \\ ${ }^{2}$ Payam Noor University professor and faculty of the Department of Educational Sciences \\ *Corresponding Author: mjkaramafrooz@yahoo.com
}

Copyright (C) 2013 Horizon Research Publishing All rights reserved.

\begin{abstract}
Cognitive learning styles are relatively fixed procedures using which individuals receive, process and organize information. This paper aims to examine academic achievement in English for both field dependence and field independence learning styles using educational multimedia. The sample of the study consisted of 40 second-grade female students of secondary school in Kermanshah. The instrument used in the study was The Group Embedded Figures Test (GEFT) and a teacher made English test. Results which were analyzed by t-test indicated that instruction based on field dependence style with using multimedia works were more effective in improving students' creative thinking performance in student than field independence. Also in field dependence style students will have a better memory to memorize verbal information, whereas in field independence one students act analytically toward the main subject materials. Interestingly, in field dependence style students have a higher interest in continuing their study than in field independent style, as a result they are more successful in utilizing what their environment according to their needs.
\end{abstract}

Keywords Academic Achievement, Instructional Multimedia, Field Dependence, Field Independent, Cognitive Style

\section{Introduction}

Discussions about learning styles became more frequent from the last decades of 1970s. A great number of researchers believe that learning styles influence learning itself. Although the term "learning styles" is defined in a number of ways and has diverse definitions, all the definitions affirm that learning styles include opinions, beliefs, preferences, and behaviors people deploy in a specific situation to improve their learning.

Research findings confirm the importance of learning styles and their influence on meaningful learning. Learning style refers to the way a person learns something. It also refers to the particular strategies through which people comprehend specific information in the process of learning. Learning styles also include opinions, preferences, and behaviors that are employed by people in the process of learning.

Learning styles include the three cognitive, physiological, and emotional domains:

1. Cognitive learning style is related to the understanding, acquiring information, and the solving of the problem used by the learner.

2. Emotional learning style is related to the learner's personality and her/his emotional characteristics.

3. And physiological learning style includes the learner's reactions to the environment and its physical conditions.

Cognitive learning styles are numerous, and one of them is Witkin's cognitive style. Witkin (1973), a pioneer in learning styles, defined learning styles in terms of a process. He argued that learning styles are concerned with the form rather than the content of the learning activity. Learning style refers to individual differences in how we perceive, think, solve problems, and learn. Witkin spent a great part of his academic career developing measures of learning style. His work concentrated on determining to what extent a person's perception of an item was influenced by the surrounding field in which the item appeared. He wanted to determine if "some people saw the tree, while others saw the forest". According to him whereas field-dependent people see the forest, field-independent learners see the tree within the forest.[9]

Therefore, in cognitive learning style, divides people into two field-dependent and field-independent groups and maintains that field-dependent people are more successful in learning and remembering social materials. But, the field-independent are more successful in learning and remembering materials which are not social. Likewise, field-dependent teachers favor communication with the learners as well as class discussions while field-independent teachers prefer a formal class atmosphere and emphasize cognitive and theoretical dimensions. It is necessary for teachers to be aware of them as well as their types in order to 
be able to help them in taking advantage of different learning styles. Teachers also need to adopt their own educational and communication styles as much as possible to their students' learning styles and save students the right to act and learn, at least sometimes, according to their own learning styles. Researchers have shown that students learn differently under the same circumstances. Moreover, they employ different methods for studying their courses, and these methods are formed to some extent under the influence of their learning styles as well as the content of the course.

Different studies have discovered the relationship between one's personal traits and their filed-dependency or filed-independency. Some of the characteristics of field-dependent people are: passivity, dependence, and approval, whereas the traits of field-independent ones include courage, independence, and improvement.

Researchers have indicated that students learn differently under the same circumstances. Moreover, they employ different methods for studying their courses, and these methods are formed to some extent under the influence of their learning styles as well as the content of the course.

The conducted researches illuminate that the field-dependent are more successful in learning already organized materials than in learning those materials that are not organized enough. The field-independent, however, better understand those materials they organize themselves than those materials already organized. A point to be noted here is the extent to which educational media can mediate in the learning process and whether these media can influence people's learning styles. In other words, since one of the most exciting and innovative events in education in recent years has been the employment of new educational technologies, what is the role of such educational technologies in learning in different styles?

These technologies have reinvigorated many classes. Teaching the sciences by the use of new devices in laboratories has been revitalized. Video tapes and films have brought the real world into the classes. Despite this, we are still at an early stage in the educational and learning technology revolution. Computers enable the teachers to radically alter learning environments. The rate of the development of new educational technologies (as meaningful segments of education) is still unknown. Noticeable developments are being achieved in this regard [2].

Research on the physiology of mind and the psychology of cognition has challenged the traditional model of learning the objective of which was good command of facts and ides, and directs specialists to more recent theories like constructivism. Constructivism as a theory believes that knowledge is the result of the continuous interaction of the learner with the available constructions for a better understanding of the world [3]. In other words, constructivists hold that learning is a dynamic process and that the learners construct their personal knowledge by choosing and communicating information and create hypotheses and decisions. One of the implications of this theory is to take into account the motivations of the learners. According to the theory of constructivism, it is the learner who is the center and basis of education. Meaningful learning happens when the students find effective ways to solve problems and when qualified learning happens.

Although qualified learning may differ in detail, it is generally accepted that in order for learning to take place, the learners should be motivated. Fundamental concepts must be understood and knowledge must develop through more complicated and more elevated thinking skills. Information and communication technologies cycle representation systems by the use of different kinds of stimuli (photo, sound, and movement) and fulfill the requirements of different kinds of learning (cognitive, emotional, mental, and kinesthetic) [4].

In our country, students start learning English at a general level (general English) from the first grade in secondary school to the end of their high school and by entrance into university they must pass special English courses (English for specific purposes) in that the presupposition is that by the end of high school they know English at a general level. What we observe, however, is that most English learners have difficulties with English not only after finishing their general education but even after the graduation from university.

The findings of the researches conducted in the field of education indicate the importance of learning styles and their influence on meaningful learning. 'Learning styles' refer to the ways a person learns. It also signifies the diverse methods through which people comprehend the information in the learning process. Learning styles are also beliefs, preferences, and behaviors that are employed by people in the learning process. Accordingly, it is necessary to study the effects of educational technology -which is of great importance in learning - on learning styles.

The present study compares and contrasts the performance as well as the degree of learning English in the two styles of field-independent and field-dependent that has been educated by the use of multimedia. Accordingly, the following questions are dealt with in order to determine whether employing educational multimedia has the same effects on field-dependent and field-independent learners or not. Therefore, the findings obtained from the study of the following hypotheses are reported in this article:

- 1.There is a difference in the performance of the field-dependent and field-independent students who have been educated by employing multimedia.

- 2.There is a difference in the scores of the English exam of the field-dependent and field-independent students who have been educated by employing multimedia.

- 3.Field-independent students are at a higher level in analyzing comprehension compared to field-dependent students.

- 4.Field-dependent students have a better memory concerning verbal information than the 
field-independent students.

\section{Materials and Methods}

\subsection{Methodology}

This research is an applied one which was quasi-experimentally conducted. The population under study was 200 Islam Abad female students at the second grade in secondary (guidance) school who were studying in ten separate classes in the Academic year 2010-2011. At first, in this group of 200 students the so-called "Embedded Figures Test" (EFT) was conducted according to the results of which students were divided into the two groups of field-dependent and field-independent. Then, 20 students were chosen simple randomly among the field-dependent students. Likewise, 20 students were randomly chosen among the field-independent students. The sum total of the sample accordingly was 40 who were chosen by controlling the variables of age, gender, subject, teacher, and the level of education for the purpose of achieving homogenized groups.

Before educating the groups by the use of multimedia, a teacher-made achievement test was conducted to measure the performance level of the students (pre-test). At the end, after educating both groups by the use of multimedia, this exam was once more conducted (post-test), and after comparing the performance of the two groups, the results of the pre-test and post-test were likewise compared.

This project has two independent variables, namely the method of education (education through educational multimedia) and the two cognitive styles of field-independency and field-dependency the influence of which on the dependent variable of learning was studied. Learning includes the achieved scores of the students which were obtained through achievement tests. The instrument employed for the accumulation of the data in this research includes two tests.

The first test is the group version of the Embedded Figures Test (GEFT) (which shows the degree of field-dependency and field-independency of the samples). This test was developed by Witkin and Ultman in 1971 [6]. It is consisted of three component parts. The first part includes 7 pictures which are offered for practice and must be conducted in 12 minutes. Each of the second and third parts consists of 9 pictures and each is conducted in 5 minutes to measure the scores of the test based on the second and third parts. The range of the score of the test varies from 0 (complete dependence) to 18 (complete independence). The higher the score of the taste, the more field-independent $s / h e$ is.

The second test is a teacher-made achievement test in English (which indicates the level of performance and learning of the samples). The test consists of 20 questions which are devised by a number secondary school (guidance school) English language teachers.

\subsection{Statistical Analysis}

\subsubsection{Hypothesis}

There is a meaningful difference between the performance of field-independent and field-dependent students who are educated by the use of multimedia.

Table (1), independent $T$ test shows the meaningful Mean difference of field-dependent students' scores and those of the field-independent students.

Table (1) shows that since $t$ is 2.689 and the significance level is 0.01 which is less than 0.05 ( $\mathrm{sig}<0.05)$ which in turn shows that the difference the two groups is meaningful, then the hypothesis zero is rejected and its antithetical hypothesis is accepted. The first hypothesis is accordingly accepted. As a result, there is a 95 percent chance for a meaningful difference to exist between the performance of field-independent and filed-dependent students who are educated by multimedia.

\subsubsection{Hypothesis}

field-dependent students who are educated by the help of multimedia have a better performance compared to field-independent students who are educated by the use of educational media.

Table (2): independent $t$ test shows the meaningfulness of field-dependent students' better performance compared to field-independent students.

Table (2) shows that since the $\mathrm{T}$ equals 2.799 with a significance level of 0.01 which is less than $0.05(\mathrm{sig}<0.05)$ which shows that the Mean difference is meaningful, hypothesis zero is rejected and its antithesis, i. e., hypothesis 1 , is confirmed. Moreover, since the Mean of the field-dependent group is higher, hypothesis number 2 is confirmed. Accordingly, there is a 95 percent chance for the field-dependent students who are instructed by the help of multimedia to have a better performance compared to the field-independent students who are educated by using educational media.

\subsubsection{Hypothesis}

In teaching by the help of multimedia, field-independent students are more analytical concerning the main content than the field-dependent students.

Table (3), independent $\mathrm{T}$ test indicates the meaningfulness of the Mean difference in the scores of field-dependent and field-independent students concerning the main content.

Table( 3 ) indicates that since the $\mathrm{T}$ equals 2.989 with a significance level of 0.01 which is less than 0.05 ( $\mathrm{sig}<0.05)$ which in turn shows that the Mean difference between the scores of the two groups is meaningful, then hypothesis zero is rejected and its antithesis is accepted. Therefore, hypothesis 3 is accepted. Accordingly, in teaching by the help of multimedia, there is a chance of 95 percent for filed-independent students to be more analytical concerning the main content than the field-dependent students. 


\subsubsection{Hypothesis}

In teaching by employing multimedia, the field-dependent students have a better memory for data and topics which are verbally expressed compared to the field-independent students.

Table (4) independences $T$ test for indicating the meaningfulness of the Mean difference in the scores of field-dependent and field-independent students in expressing the content.

Table( 4 ) indicates that since $\mathrm{T}$ is 2.578 with a significance level of 0.01 that is less than $0.05(\mathrm{sig}<0.05)$ which shows that the Mean difference of the two groups concerning the expression of the main content is meaningful, hypothesis zero is rejected and its antithetical hypothesis is accepted. Accordingly, there is a chance of 95 percent that field-dependent students who are instructed by the help of multimedia have a better memory for those information and subjects which are verbally expressed compared to their peer field-independent student.

Table 1. Independent $\mathrm{T}$ test

\begin{tabular}{|c|c|c|c|c|c|c|c|}
\hline Group & Number & Mean & Standard Deviation & $\begin{array}{c}\text { Mean } \\
\text { Differences }\end{array}$ & $\begin{array}{c}\text { Degree of } \\
\text { Freedom }\end{array}$ & $\begin{array}{c}\text { T test } \\
\text { Significance } \\
\text { Level }\end{array}$ \\
\hline field-dependent & 20 & 35.05 & 8.605 & 3.150 & 38 & 2.689 & .01 \\
\cline { 1 - 4 } Field-independent & 20 & 26.90 & 10.473 & & & \\
\hline
\end{tabular}

Table 2. Independent $t$ test

\begin{tabular}{|c|c|c|c|c|c|c|c|}
\hline Group & Number & Mean & $\begin{array}{c}\text { Standard } \\
\text { Deviation }\end{array}$ & $\begin{array}{c}\text { Mean } \\
\text { Differences }\end{array}$ & $\begin{array}{c}\text { Degree of } \\
\text { Freedom }\end{array}$ & T test & Significance Level \\
\hline field-dependent & 20 & 36.05 & 9.605 & 9.150 & 39 & 2.799 & .01 \\
\cline { 1 - 4 } Field-independent & 20 & 27.90 & 11.473 & & \\
\hline
\end{tabular}

Table 3. Independent $\mathrm{T}$ test

\begin{tabular}{|c|c|c|c|c|c|c|c|}
\hline Group & Number & Mean & Standard Deviation & $\begin{array}{c}\text { Mean } \\
\text { Differences }\end{array}$ & $\begin{array}{l}\text { Degree of } \\
\text { Freedom }\end{array}$ & $\mathrm{T}$ test & $\begin{array}{c}\text { Significance } \\
\text { Level }\end{array}$ \\
\hline field-dependent & 20 & 9.573 & 10.67 & 7.160 & 40 & 2.989 & .01 \\
\hline Field-independent & 20 & 26.90 & 10.473 & & & & \\
\hline
\end{tabular}

Table 4. Independence T test

\begin{tabular}{|c|c|c|c|c|c|c|c|}
\hline Group & Number & Mean & Standard Deviation & $\begin{array}{c}\text { Mean } \\
\text { Differences }\end{array}$ & $\begin{array}{c}\text { Degree of } \\
\text { Freedom }\end{array}$ & $\begin{array}{c}\text { T test } \\
\text { Significance } \\
\text { Level }\end{array}$ \\
\hline field-dependent & 20 & 20.83 & 8.709 & 8.170 & 37 & 2.578 & .01 \\
\hline Field-independent & 20 & 8.82 & 7.473 & & & & \\
\hline
\end{tabular}




\section{Conclusion}

This article analyses the findings which were achieved in studying the effects of employing educational multimedia on the achievement of the students with the cognitive styles of field-independency and field-dependency in the English course of the second grade of secondary (Guidance) school. It is an applied research wherein the Embedded Figures Test (EFT) was employed to determine the group's cognitive styles and the following findings were achieved:

Comparing the performance of the students who are educated by the help of multimedia in the two groups of field-independent and field-dependent indicates that the Mean difference between the two groups is statistically meaningful. In other words, there is a difference in performance of these students all of whom are educated by employing multimedia.

In this regard there are also other researches' conducted before which confirmed the difference in the performance of the field-dependent and the field-independent. For instance, "Ridring and colleagues" [7] in their researches concluded that field-dependent students have a tendency for external and visual guidance whereas field-independent students have a better comprehension and understand the materials rapidly without any visual and audio guidance. Educational multimedia can supply the field-dependent person or groups with organized programs of learning experience in which there is a strong emphasis on learning by the help of the senses. The main objective of developing such multimedia is to combine instruments in the best possible way in order to fulfill environmental needs of special contents by taking into account, at the same time, the learners' abilities and shortcomings, infrastructures, and the systematic conditions of the learning environment [4].

In a study conducted by Fleming in 1968 a list of words which could differentiate the field-dependent students from the field-independent was given to them. In this test the testers were asked to arrange the words in any arbitrary fashion they liked. Then they were measured. What the study indicated was that field-dependent people were more successful when the words were offered in a hierarchical way while the field-independent were more successful in remembering the words when the words were not coherent or organized enough.

Nowrouzi [6] has referred to these conducted researches in his study of cognitive styles and their relationship to learning, and claims that in a research applied on university students by Renzi [5] the result was that when the feedback of the material is presented immediately after, the field-dependent students are more successful than the field-independent [6]. As it was expected, the results of present research bear considerable affinity with the other researches' conducted in the field.

Comparing the performance of field-dependent students who were educated by applying multimedia with the field-independent students who were also instructed by multimedia indicates meaningful Mean difference between the two groups. Consequently, hypothesis zero is rejected and its antithetical hypothesis is accepted. Also, since the Mean of the field-dependent group is higher, it can be inferred that field-dependent students educate by multimedia have a better performance than field-independent students instructed by educational media[8].

Another investigation in this regard shows that in field dependent multimedia instruction students have a better memory for verbal information.

Abstract interactive learning using compact disks and internet or distant learning requires kinds of memory and motivation. Learning words that describe some conditions is better to have a good memory and teachers must teach students a list of words to enhance their learning. Using media in the form of visual and audio stimuli can help you in this way.

\section{REFERENCES}

[1] M. Hosseini Lorgany, Comparison of learning style bachelor and Master of Science degree in weak and strong men and women, medical and engineering universities. MSc. thesis. Allameh Tabatabai University, Iran, 1998.

[2] SH. Zufan, Kh. LotfyPour, Production and use of Materials, Tehran, printing and distribution of Iran textbooks, 2000. pp 3-51.

[3] S.A. Razavi, New Issues in Educational Technology, Ahwaz Shahid Chamran University, 2007, P 3.

[4] H. Wadi, D. Alexandra, Technology for Learning, abilities, values and perspectives, translated by M.R. Srkarany, A.R. Moghadam, Tehran, Ney, 2002, P 80.

[5] HA. Witkin, Field-Dependent and Field-Independent Cognitive Styles and Their Educational Implications, Review of Educational Research, winter 1977, Vol. 47: 1-64.

[6] D. Nowurozi, Cognitive styles and their relation to learning. Proceedings of Humanities and Sciences and Psychology, Tehran, Islamic Azad University, South Branch, 2003.

[7] R. Riding, I. Cheema, Cognitive styles, an overview and integration. Educational Psychology, 1991.Vol.11, 193-216.

[8] E. Zvarky Zarei, F. Jfrkhany, multi-media education and its role in special education. Tehran: Institute for Humanities and Cultural Studies, 2009.

[9] Witkin, H.A. (1973). The role of cognitive style in academic performance and in teacher- student relations. Paper presented at a symposium on Cognitive Styles, Creativity and Higher Education. sponsored by the Graduate Record Examination Board, Montreal, Canada. Princeton, N.J.: Educational Testing Service, Research Bulletin 73 - 11. 